\title{
Stunting and Associated Factors Among Children Aged 6-59 Months From Households in Productive Safety Net Program and Non-productive Safety Net Program in Meta District, East Hararghe Zone, Eastern Ethiopia: a Comparative Cross - Sectional Study.
}

Aklilu Tesfaye

Chelenko District Health Office, east Hararghe

Gudina Egata ( $\nabla$ gudina_egata@yahoo.com )

Addis Ababa University https://orcid.org/0000-0001-6541-0383

\section{Research article}

Keywords: Children 6 to 59 months, Ethiopia, PSNP, stunting

Posted Date: August 3rd, 2021

DOl: https://doi.org/10.21203/rs.3.rs-757635/v1

License: (c) (i) This work is licensed under a Creative Commons Attribution 4.0 International License. Read Full License 


\section{Abstract}

Background: Undernutrition is one of the major public health problems affecting children in developing settings. Despite impressive interventions such as productive safety net program (PSNP) in Ethiopia, there is paucity of information on the prevalence of stunting and its predictors among children aged 6-59 months born to beneficiaries and non-beneficiaries of the program in Ethiopia.

Methods: Community based comparative cross sectional study design was used among randomly selected 1555 children aged 6 to 59 months from households using and not using PSNP respectively in Meta distinct from $5^{\text {th }}-20^{\text {th }}$ of March, 2017. Data were collected using pre-tested structured questionnaire. Measuring board was used to measure the length/height of the children. Length/height for age z-score was generated using world Health Organization (WHO) Anthros version 3.2.2. Descriptive statistics was used to describe all relevant data. Bivariable and Multivariable logistic regression analyses were used to predictors of the outcome variable. Odds ratio along with $95 \%$ confidence interval were estimated to measure the strength of the association. Level of statistical significance was declared at p-value less than 0.05 .

Result: The prevalence of stunting was $47.7 \%, 95 \% \mathrm{Cl}$ : (44.1\%, 51.5\%) among children from PSNP beneficiary households and $33.5 \%, 95 \% \mathrm{Cl}:(29.9 \%, 36.9 \%)$ from non-PSNP households respectively. Lack of maternal education [AOR $=3.39 ; 95 \% \mathrm{Cl}:(1.12$, 5.11)], lack of women's empowerment [AOR=3.48; $95 \% \mathrm{Cl}:(2.36,5.12)]$, non-attendance of antenatal care fourth visit [AOR=4.2, $95 \% \mathrm{Cl}(2.5,6.8)]$, practicing hand washing [AOR= 0.46; $95 \% \mathrm{Cl}:(0.28,0.76)]$, childhood illness [AOR= 8.41; $95 \% \mathrm{Cl}:(4.58,12.76)]$, non-exclusive breastfeeding $[\mathrm{AOR}=3.6 ; 95 \% \mathrm{Cl}:(2.30,4.80)]$, low dietary diversity score $[\mathrm{AOR}=4.7 ; 95 \% \mathrm{Cl}(3.0,7.40)]$, and child 's age between 24 to 59 months $[\mathrm{AOR}=3.2 ; 95 \% \mathrm{Cl}(1.6,6.3)]$ were predictors of stunting.

Conclusions: The prevalence of stunting was high among children from PSNP households in the study area. Stunting was significantly associated with maternal socio-demographic and obstetric and child related factors.

Therefore, empowering women on household's issues and improving infant and young child feeding practices could reduce the magnitude of stunting and its impacts on child health.

\section{Background}

Undernutrition is known to be one of important causes of childhood illness, disease, and disability among children of low-income countries. Undernourished children are victims of various deficiency states such as night blindness, anemia, iodine deficiency disorder, mental retardation and risk of dying compared with well- nourished children. Globally, $22.2 \%$ of under-five children were stunted. South Asia and sub-Saharan Africa (SSA) including Ethiopia have the greatest lion share of the burden of undernutrition $[1,2]$.

Stunting was one of the major nutritional problems of public health importance in Ethiopia. where $38 \%, 24 \%$, and $10 \%$ of children aged 0-59 months were stunted, underweight and wasted respectively though there is marked reginal variation within the country [3-4].

The causes of undernutrition including stunting are multifaceted in SSA including basic, underlying and proximal factors. Different studies indicated that undernutrition is attributed to maternal illiteracy, large family size, maternal age., being male child, child birth order, amount of water ( $<40$ litters) for use, lesser child age, lack of extra food during pregnancy/lactation, and low dietary diversity score (DDS below four food groups) due to household food insecurity among others in developing countries like Ethiopia [3-8].

In cognizant of this, the government of has launched productive safety net program (PSNP), one of the social protection programs implemented in SSA since 2005 being implemented in different phases as a strategy to reduce the burden of undernutrition by transferring cash and food to poor food-insecure rural households through public works of able bodied labors and direct transfers for none adult able body labor in the households [9-11], thus improving availability and access to adequate and nutritious food. The program has public work, direct support and Institutional support. Some of the public work activities include water point development, road maintenance, agro forestry, irrigation canal, schools and health post maintenance \& construction [12]. The 
national nutrition program (NNP II) was planned to implement in Ethiopia from 2016-2020, including health all sectors should be increased their efforts to enhance good nutritional practices through deferent intervention in reducing and prevention of malnutrition [13].

However, there is a paucity of evidence with regard to stunting and its predictors among children aged 6-59 months who live in productive safety net program beneficiary's households and nonbeneficiaries' households in Ethiopia particularly in the study setting. Therefore, this study was aimed at assessing the prevalence of stunting and its predictors among children aged 6-59 months from productive safety net program beneficiaries and non-productive beneficiaries' households.

\section{Methods}

\section{Study setting, period, and design}

Community based comparative cross-sectional study design was used in Meta District of East Harerge Zone of Eastern Ethiopia from 5th to 20th of March, 2017. The district has a total population of 222,016 (28,620 urban and 193,396 rural population) [14]. Chelenko is the main town of district and about $435 \mathrm{~km}$ far away from Addis Ababa, the capital city of Ethiopia. The district has 39 rural and 3 urban kebeles (smallest administrative unit in Ethiopia). The rural kebeles of the district were divided in to three agro ecological conditions (12 highlands, 15 midlands and 12 low-lands kebeles). The main ethnic groups in the district are Oromo and Amhara. The rural population was dependent up on farming. The number of functional health facility available in the district are 1 hospital, 7 health centers, 39 rural health posts and 11 different private health facilities. According to the 2017 report of Meta District disaster prevention and preparedness office (DPPO) [15], the district has 23 foods insecure rural kebeles that has been covered with PSNP and 16 food secure households. The total number of PSNP beneficiary households was 18,948 (17.5\%) of the district's population.

\section{Study Participants and sample selection}

Sample size was estimated using double population proportions formula for both PSNP beneficiaries and NPSNP households with the following assumptions: two sided $95 \%$ confidence level, $80 \%$ power, proportion of stunting among PSNP beneficiaries to be $47.0 \%$, proportion of stunting among PSNP non - beneficiaries to be $41.8 \%$ [3], desired precision of $5 \%$, and $5 \%$ for nonresponse yielding 1590 children aged 6-59 months from Productive Safety Net beneficiaries (788) and non-Productive Safety Net (671) beneficiaries households in the district. The sample size was then proportionally allocated for each selected kebeles in each arm. Initially, the rural kebeles were stratified in to high land, midland and low land agro ecology selected purposively. Totally 7 kebeles were selected randomly (3 kebele from NPSNP and 4 kebele from PSNP) to take part in the study. Children from households in each kebele for both population categories from different climatic zones were selected using a stratified random sampling method.

\section{Data collection and Measurements}

The questionnaire was initially prepared in English by reviewing relevant literature related to the study objectives and translated to "afaan Oromo" for better understanding and translated back to English by two different experts who were fluent in both languages in order to ensure the consistency of the questionnaire. Fourteen data collectors and two supervisors were involved in the process of data collection after getting the required training with regard to interview and anthropometric measurements. Sociodemographic data were collected using a pretested structured questionnaire which consisted of different sections such as questions related to socio-demographic characteristics, household's assets related questions, productive safety net membership status, maternal specific questions, child's anthropometry ,and illness two weeks before the survey Anthropometric data such as weight and height were measured following the standard procedures. Length /height was measured to the nearest $0.1 \mathrm{~cm}$. Recumbent length was measured using measuring board for children younger 24 months while height was measures for those 24 months and older in a standing position for all who can stand well by maintaining five contact points [16]. The outcome variable in this study was stunting which stands for children having height for age $Z$-score (HAZ) of less than 2 standard deviation (SD) using world health organization (WHO) new child growth. Stunting was coded as "1" for children with HAZ of less than 2SD and "0" otherwise for further analysis [17]. The explanatory variables used to identify predictors of stunting included paternal 
education, family size, maternal decision making power and working status, antenatal care visit, place of delivery, exclusive breastfeeding status, dietary diversity, hand wash practice, child's age and illness, number of under five children in the household, feeding order of the family members, and presence of child's own feeding plate (Table 3 ).

\section{Data Quality management}

Training was given for the data collectors and supervisors for two days on the objectives of the study, interview technique, and anthropometric measurements. The standardization procedure was followed to ensure reliability and validity of anthropometric measurements by computing relative technical error of measurement (TEM) using Emergency Nutrition Assessment Standardized Monitoring and Assessment of Relief and Transitions (ENA SMART) software to compare measurements done by each data collector with selected criterion anthropometrist before deploying the data collectors to the field to minimize both random and systematic errors attributed to inaccurate anthropometric measurement. Accordingly, the relative TEM for inter observer (validity) and intra observer (reliability) for length /height measurement was $1.5 \%$ and $2.0 \%$ respectively [18]. The questionnaire was pretested one week before the actual task of data collection on $5 \%$ of the estimated sample size for the study in kebeles not included in the study. The whole process of data collection was supervised by supervisors in the field on daily basis for completeness of each questionnaire. Data were double entered by two data clerks and consistency was crosschecked. Multivariable analysis was done to control for all possible confounders that might mask the true association between independent and outcome variable.

\section{Statistical analysis}

Data were manually checked for completeness, edited, double entered onto Epi-Data version 3.1, cleaned, and exported to SPSS version 20 statistical package computer software for further analysis. Moreover, anthropometric indices were also generated using WHO Anthros software version 3.2.2 and coded based on WHO's cut-off points to serve as outcome variables Descriptive statistics was such as numerical summary measures and frequency distribution were used to describe each independent variable relative to the outcome variable. The independent variables were coded based on previous related studies and distribution of responses in the data. Bivariable logistic regression analyses were done to see the association between dependent variable and each independent variable. All covariates with $p$ value $<0.25$ during bivariable analyses were considered for multivariable analysis to control for all possible confounders and to identify factors associated with stunting. The multicollinearity effect between independent variables was checked by looking at values of the standard error and correlation coefficient. Variables with standard error $>2$ and correlation coefficient of less than $50 \%$ were dropped from final logistic regression model. The fitness of the model was tested by Hosmer- Lemeshow goodness of fit test whereby $p$ - value $=0.631$ for stunting. Odd ratios along with $95 \%$ confidence interval were estimated to measure the strength of the association. Level of statistical significance was declared at $p$ value less than 0.05 .

\section{Results}

\section{Socio-demographic characteristic of the study participants}

A total of 1,555 (97.8\%) of respondents were participated in the study making a response rate of $97.8 \%$ of which 782 (98.4\%) participated form PSNP while 773 (97.2\%) participated from NPSNP. Among 782 PSNP respondents 153 (19.6\%), 403 (51.5\%) and 226 (28.9\%) were participated from high-land, mid-land and low-land respectively. Among NPSNP 773 respondents, 390 (50.5\%), 224 (29\%) and 159 (20.6\%) were participated from high-land, mid-land and low-land respectively. The mean ( \pm SD) age of mothers/ caretakers from the high-land was $(29.0 \pm 6.34)$ years, midland $(30 \pm 6.68)$ years and low-land $(30 \pm 6.678)$ years respectively. Most of the respondents 1504(96.7\%) was Oromo by their ethnicity while 51(3.3\%) was Muslim by their religion. Nearly $94 \%$ of the mothers / care takers were married. About $11.6 \%$ of the mothers and $25.5 \%$ of their husbands have formal educations. The majority (89.8\%)) of the mothers were house wives by their occupation while $95.8 \%$ of their husbands were farmers. The majority $(27.2 \%)$ of the mothers/ care takers belong to the poorest households. Nearly equally proportion of mothers/care takers were from the three agroecological areas though most of the mothers from PNSP programs belong to the poorest segment $(40.2 \%$, ) compared to those from NPSP $(14.1 \%)$ (Table 1$)$. 
Table 1

Socio demographic characteristics parents with children aged 6-59 months, Meta district east Ethiopia 2017.

\begin{tabular}{|c|c|c|}
\hline \multirow[t]{2}{*}{ Variables $(n=1555)$} & PSNP HH'S & NPSNP HH's \\
\hline & number (\%) & number (\%) \\
\hline \multicolumn{3}{|l|}{ Mother education status } \\
\hline Have no formal education & $685(87.6)$ & $571(73.9)$ \\
\hline Read and write only & $27(3.5)$ & $90(11.6)$ \\
\hline Primary school & $51(6.5)$ & $53(6.9)$ \\
\hline Secondary school & $19(2.4)$ & $51(6.6)$ \\
\hline Diploma/Degree & $0(0)$ & $8(1)$ \\
\hline \multicolumn{3}{|l|}{ Father education status } \\
\hline Have no formal education & $505(64.6)$ & $442(57.2)$ \\
\hline Read and write only & $112(14.3)$ & $100(12.9)$ \\
\hline Primary school & $132(16.9)$ & $113(14.6)$ \\
\hline Secondary school & $25(3.2)$ & $83(10.7)$ \\
\hline Preparatory & $8(1)$ & $21(2.7)$ \\
\hline Diploma/Degree & $0(0)$ & $14(1.8)$ \\
\hline \multicolumn{3}{|l|}{ Maternal Occupation } \\
\hline Home lady & $676(86.4)$ & $721(93.3)$ \\
\hline Farmer & $12(1.5)$ & $11(1.4)$ \\
\hline Teacher & $0(0)$ & $12(1.6)$ \\
\hline Civil Servant & $0(0)$ & $4(0.5)$ \\
\hline Merchant & $94(12)$ & $25(3.2)$ \\
\hline \multicolumn{3}{|l|}{ Father Occupations } \\
\hline Farmer & $782(100)$ & 708(91.6) \\
\hline Civil Servant & $0(0)$ & $16(2.1)$ \\
\hline Teacher & $0(0)$ & $17(2.2)$ \\
\hline Merchant & $0(0)$ & $12(1.6)$ \\
\hline No Job (Jobless) & $0(0)$ & $20(2.6)$ \\
\hline \multicolumn{3}{|l|}{ Ethnic of the respondent } \\
\hline Oromo & $772(98.7 \%)$ & $732(94.7 \%)$ \\
\hline Amhara & $10(1.3 \%)$ & $41(5.3 \%)$ \\
\hline \multicolumn{3}{|l|}{ Marital status } \\
\hline Married & $723(92.5 \%)$ & 724(93.7\%) \\
\hline Divorced & $4(.5 \%)$ & $13(1.7 \%)$ \\
\hline Widowed & $43(5.5 \%)$ & $11(1.4 \%)$ \\
\hline
\end{tabular}

Page 5/16 


\begin{tabular}{|lll|}
\hline Variables ( $\mathbf{n}=1555)$ & PSNP HH's & NPSNP HH's \\
\cline { 2 - 3 } & number (\%) & number (\%) \\
\hline Separate & $12(1.5 \%)$ & $25(3.2 \%)$ \\
\hline Mother age & & \\
\hline 18-44 years & $742(95.3 \%)$ & $762(98.6 \%)$ \\
\hline 45 and more years & $40(5.1 \%)$ & $11(1.4 \%)$ \\
\hline Family size & & \\
\hline 0-4 family & $127(16.2)$ & $399(51.6)$ \\
\hline 5-8 family & $528(67.5)$ & $321(41.5)$ \\
\hline 9 and more & $127(16.2)$ & $53(6.9)$ \\
\hline Agro ecology & & \\
\hline High land & $153(19.6 \%)$ & $390(50.5 \%)$ \\
\hline low land & $403(51.5 \%)$ & $224(29 \%)$ \\
\hline Mid-land & $226(28.9 \%)$ & $159(20.6 \%)$ \\
\hline Wealth Index & & \\
\hline Poorest & $138(17.6)$ & $292(37.8)$ \\
\hline Poor & $28(3.6)$ & $122(15.8)$ \\
\hline Medium & $128(16.4)$ & $92(11.9)$ \\
\hline Rich & $174(22.3)$ & $158(20.4)$ \\
\hline Richest & & \\
\hline
\end{tabular}

\section{Maternal health care service utilization and Women's participation in decision making on the household issues}

About half (55.2\%) of women attended antenatal care service up to 4 visits (ANC IV) at health facilities; (49.3\% in PSNP and $61.4 \%$ in NPSNP). Almost two-third (63.7\%) of the women were utilizing family planning services, (56.3\% in PSNP and $71.3 \%$ in NPSP households). The most commonly used birth control methods were Depo-Provera (40.8\%) followed by implant (17.8\%). About $42.6 \%$ of the women were married before 18 years. The mean $( \pm S D)$ age at first marriage was $17.65( \pm 2.279)$ years. About $59.7 \%$ of the married women gave birth to the first baby prior to celebrating their 20 years' birthday. The mean ( \pm SD) age at the first delivery for the mothers was $19.16( \pm 2.617)$ years (Table 2$)$. 
Table 2

Selected maternal and child's characteristics among the study participants from PNSP and NPNSP households, Meta District, March 2017.

\begin{tabular}{|c|c|c|c|c|c|c|}
\hline \multirow[t]{2}{*}{ Variables $(n=1555)$} & \multicolumn{2}{|c|}{ Membership of PSNP } & \multicolumn{2}{|c|}{ Non membership of PSNP } & \multicolumn{2}{|l|}{ Total } \\
\hline & Number & Percentage & Number & Percentage & Number & Percentage \\
\hline \multicolumn{7}{|c|}{ Did you have antenatal care follow-up } \\
\hline Yes & 422 & 54 & 242 & 31.3 & 664 & 42.7 \\
\hline No & 360 & 46 & 531 & 68.7 & 891 & 57.3 \\
\hline \multicolumn{7}{|c|}{ Did you use birth control } \\
\hline Yes & 440 & 56.3 & 551 & 71.3 & 991 & 63.7 \\
\hline No & 342 & 43.7 & 222 & 28.7 & 564 & 36.3 \\
\hline \multicolumn{7}{|c|}{ Method of birth control } \\
\hline IUCD & 3 & 0.4 & 2 & 0.3 & 5 & 0.3 \\
\hline Implant & 104 & 13.3 & 173 & 22.4 & 277 & 17.8 \\
\hline Depo-Provera & 256 & 32.7 & 378 & 48.9 & 634 & 40.8 \\
\hline Pills & 74 & 9.5 & 0 & 0 & 74 & 4.8 \\
\hline \multicolumn{7}{|l|}{ Age of marriage } \\
\hline$<18$ years & 439 & 56.1 & 224 & 29 & 663 & 42.6 \\
\hline$\geq 18$ years & 343 & 43.9 & 549 & 71 & 892 & 57.4 \\
\hline \multicolumn{7}{|l|}{ Age of 1 st delivery } \\
\hline$<20$ years & 497 & 63.6 & 431 & 55.8 & 928 & 59.7 \\
\hline$\geq 20$ years & 285 & 36.4 & 342 & 44.2 & 627 & 40.3 \\
\hline \multicolumn{7}{|l|}{ place of birth } \\
\hline Health facility & 503 & 64.3 & 537 & 69.5 & 1040 & 66.9 \\
\hline Home delivery & 279 & 35.7 & 236 & 30.5 & 515 & 33.1 \\
\hline \multicolumn{7}{|c|}{ woman participation in decision making } \\
\hline Yes & 296 & 37.9 & 350 & 45.3 & 646 & 41.5 \\
\hline No & 486 & 62.1 & 423 & 54.7 & 909 & 58.5 \\
\hline \multicolumn{7}{|c|}{ Hand washing practice } \\
\hline Yes & 171 & 21.9 & 122 & 15.8 & 293 & 18.8 \\
\hline No & 611 & 78.1 & 651 & 84.2 & 1262 & 81.2 \\
\hline \multicolumn{7}{|c|}{ Did a Mother breast feed her children } \\
\hline Yes & 771 & 98.6 & 752 & 97.3 & 1523 & 97.9 \\
\hline No & 11 & 1.4 & 21 & 84.2 & 32 & 2.1 \\
\hline \multicolumn{7}{|c|}{ Exclusive breast feeding } \\
\hline Yes & 399 & 51 & 472 & 61.1 & 871 & 56 \\
\hline No & 383 & 49 & 301 & 38.9 & 684 & 44 \\
\hline
\end{tabular}




\begin{tabular}{|c|c|c|c|c|c|c|}
\hline \multirow[t]{2}{*}{ Variables $(n=1555)$} & \multicolumn{2}{|c|}{ Membership of PSNP } & \multicolumn{2}{|c|}{ Non membership of PSNP } & \multicolumn{2}{|l|}{ Total } \\
\hline & Number & Percentage & Number & Percentage & Number & Percentage \\
\hline \multicolumn{7}{|c|}{ Age of discontinuation of breast feeding } \\
\hline$<6$ months & 27 & 3.5 & 33 & 4.3 & 60 & 3.9 \\
\hline 6-11 month & 4 & 0.5 & 0 & 0 & 4 & 0.3 \\
\hline $12-23$ month & 751 & 96 & 740 & 95.7 & 1491 & 95.9 \\
\hline \multicolumn{7}{|c|}{ Age of introducing Complimentary feeding } \\
\hline$<6$ months & 42 & 5.4 & 62 & 8 & 104 & 6.7 \\
\hline At 6 Month & 426 & 54.5 & 548 & 70.9 & 974 & 62.6 \\
\hline$\geq 7$ months & 314 & 40.2 & 163 & 21.1 & 477 & 30.7 \\
\hline \multicolumn{7}{|l|}{ Dietary diversity } \\
\hline$<4$ food groups & 384 & 49.1 & 299 & 38.7 & 683 & 43.9 \\
\hline$\geq 4$ food groups & 398 & 50.9 & 474 & 61.3 & 872 & 56.1 \\
\hline
\end{tabular}

\section{Child feeding practices}

Almost all mothers (98.1\%) breastfed their children of which only $44.2 \%$ of the mothers -exclusively breastfed their children (47.4\% in PSNP and 33.7\% in NPSNP households). About $-21.4 \%$ of the mother started first complimentary food at 6 months. The first complimentary food given to the children was Porridge (55.6\%), animal milk and Porridge (19.4\%) respectively.

\section{Prevalence of stunting among children aged 6-59 months}

The overall prevalence of stunting was $40.6 \%$; $95 \% \mathrm{Cl}$ : (38.3\%, 43.3\%) among children aged 6-59 months in the study setting. The prevalence of stunting was $47.7 \% ; 95 \% \mathrm{Cl}(44.1 \%, 51.5 \%)$ among children aged $6-59$ months from productive safety net program beneficiaries' areas and $35.5 \% ; 95 \% \mathrm{Cl}(29.9 \%, 36.9 \%)$ among those children from non-productive safety net beneficiary households. Stunting is also more common among children from PSNP beneficiaries' households compared to non-PSNP beneficiaries' households (Fig. 1).

This study also showed that male children were more stunted than female children. The prevalence of stunting among male children were $51.5 \%$ for PSNP beneficiary households and 33.8\% for NPSNP households while the prevalence of stunting among female children were $44.2 \%$ for PSNP beneficiary households and $33.2 \%$ for NPSNP households. The overall prevalence was showed that $42.6 \%$ for male children and $38.8 \%$ for female children (Fig. 2).

Stunting is also more common among all agroecological settings namely highland, midland, and low land. However, stunting was more common among children from PSNP and NPNSP households living in the midland areas compared to their counterparts (highland and lowland). The prevalence of stunting in the highland, mid-land, and low -land were $32.6 \%, 57.1 \%$, and $25.2 \%$, respectively (Fig. 3).

\section{Predictors of stunting among children aged 6-59 months.}

In multivariable logistic regression analysis, lack of maternal education, women's inability to make decision on households issues, lack of fourth antenatal care visit, practicing of hand washing during the critical periods, history of frequent attack by childhood illness, lack of exclusive breastfeeding, eating less diversified foods, and child 's age (24-59 months) were significantly associated with stunting.

Children born to mothers who have not formal education were 3.39 times [(AOR $=3.39 ; 95 \% \mathrm{Cl}:(1.12,5.11)]$, more likely to be stunted than children born to educated mothers. Stunting was 3.5 times [(AOR $=3.48 ; 95 \% \mathrm{Cl}:(2.36,5.12)]$ more common among 
children whose mothers lacked decision making power at household level than those whose mothers could decide on household matters. Children who born to mothers who did not have antenatal care service (ANC IV) during their pregnancy were 4.2 time [(AOR $=4.2 ; 95 \% \mathrm{Cl}(2.5,6.8)]$ more likely to be stunted compared with their counterparts. The odds of stunting was reduced by $54 \%$ [(AOR $=0.46 ; 95 \% \mathrm{Cl}:(0.28,0.76)]$ among children from households who practiced hand washing during the critical periods (before eating and preparation of food, before child feeding, after use of latrine and after disposing of infant stool) compared with their counterparts. Children who were repeatedly affected with childhood illness were 8.4 times [(AOR $=8.41 ; 95 \% \mathrm{Cl}:(4.58,12.76)]$ more likely to be stunted than their counter parts. The odds of stunting were nearly 4 times [(AOR $=3.6 ; 95 \% \mathrm{Cl}$ : $(2.3,4.8)]$ higher among children who were not exclusively breastfed compared with their counterparts. Children who have fed on less diversified foods were nearly five times $[(A O R=4.7 ; 95 \% \mathrm{Cl}(3.0,7.4)]$ more likely to be stunted compared to those who have fed on adequately diversified foods. Children in the age bracket of $24-59$ months were three times $[(\mathrm{AOR}=3.2 ; 95 \% \mathrm{Cl}:(1.6,6.3)] \mathrm{more}$ likely to be stunted compared with younger ones. The odds of stunting were 1.94 times $[(\mathrm{AOR}=1.94 ; 95 \% \mathrm{Cl}:(1.12,3.35)] \mathrm{more}$ likely among children from midland ecologic zone compared with those form the high land. In contrary, the odds of stunting were reduced by $73 \%[(\mathrm{AOR}=0.27 ; 95 \% \mathrm{Cl}:(0.16,0.45)]$ among children from low land ecologic zone compared with those from the highland. The odds of stunting were 1.73 times higher [ $(A O R=1.73 ; 95 \% \mathrm{Cl}:(1.18,2.53)]$ among male children compared with their counterparts. Moreover, stunting was found to be 1.82 times $[(\mathrm{AOR}=1.8 ; 95 \% \mathrm{Cl}$ : $(1.14,2.89)]$ more common among children from households enrolled in PSNP (Table 3). 
Table 3

Predictors of stunting among children aged 6-59 months in Meta District, March 2017

\begin{tabular}{|c|c|c|c|c|}
\hline \multirow[t]{2}{*}{ Variables(n = 1555) } & \multicolumn{2}{|l|}{ Stunting } & \multirow[t]{2}{*}{ COR $(95 \% \mathrm{Cl})$} & \multirow[t]{2}{*}{ AOR $(95 \% \mathrm{Cl})$} \\
\hline & Yes (\#, \%) & No (\#, \%) & & \\
\hline \multicolumn{5}{|l|}{ Maternal education } \\
\hline No formal education & $594(43.2)$ & $780(56.8)$ & 2.71: $(1.86,3.94)^{\star \star}$ & 3.39: $(1.12,5.11)^{\star \star}$ \\
\hline Have formal education & $38(22)$ & 135(78) & 1 & 1 \\
\hline \multicolumn{5}{|l|}{ Hand washing practice } \\
\hline Yes & $458(36.3)$ & $804(63.7)$ & $0.39:(0.3,0.505)^{\star \star}$ & $0.46:(0.28,0.76)^{\star \star}$ \\
\hline No & $174(59.4)$ & $119(40.6)$ & 1 & 1 \\
\hline \multicolumn{5}{|l|}{ Child illness } \\
\hline Yes & $383(70.3)$ & $162(7.7)$ & 7.23: $(5.73,9.12)^{\star \star}$ & 8.41: $(4.58,12.76)^{\star \star}$ \\
\hline No & $249(24.7)$ & $761(75.3)$ & 1 & 1 \\
\hline \multicolumn{5}{|c|}{ Child breastfeed in the first 6 months } \\
\hline No exclusively breast feed & $510(56.9)$ & $386(43.1)$ & 5.82: $(4.59,7.37)^{\star \star}$ & 3.6: $(2.3,4.8)^{\star \star}$ \\
\hline Exclusively breastfeed & $122(18.5)$ & $537(81.5)$ & 1 & 1 \\
\hline \multicolumn{5}{|c|}{ Woman participation in decision making } \\
\hline No & $503(55.3)$ & $406(45.7)$ & 4.97: $(3.93,6.27)^{\star \star}$ & 3.48: $(2.36,5.12)^{\star \star}$ \\
\hline Yes & $129(20)$ & $517(80)$ & 1 & 1 \\
\hline \multicolumn{5}{|l|}{ Antenatal care IV } \\
\hline No & $465(52.2)$ & $426(47.8)$ & 3.25: $(2.61,4.04)^{\star \star}$ & 4.2: $(2.5,6.8)^{\star \star}$ \\
\hline Yes & $167(25.2)$ & $497(74.8)$ & 1 & 1 \\
\hline \multicolumn{5}{|l|}{ Age of the children } \\
\hline 6-23months & $91(17.3)$ & $436(82.7)$ & 1 & 1 \\
\hline 24-59 months & $541(52.6)$ & $487(47.4)$ & 5.32: $(4.12,6.88)^{\star \star}$ & $3.2:(1.6,6.3)^{\star *}$ \\
\hline \multicolumn{5}{|l|}{ Dietary diversity } \\
\hline Less than 4 food items & $218(31.9)$ & $465(68.1))$ & 2.3: $(1.83,2.9)^{\star \star}$ & 4.7: $(3.0,7.4)^{\star \star}$ \\
\hline 4 food types and more & $146(16.7)$ & $726(83.3)$ & 1 & 1 \\
\hline \multicolumn{5}{|l|}{ Agro ecology } \\
\hline High-land & $177(32.6)$ & $366(67.4)$ & 1 & 1 \\
\hline Mid-land & $358(57.1)$ & $269(42.9)$ & 1.69: $(1.52,1.93)^{\star}$ & 1.94: $(1.12,3.35)^{\star}$ \\
\hline Low-land & $97(25.2)$ & $288(74.8)$ & $0.25:(0.19, .34)^{\star \star}$ & $0.27:(0.16,0.45)$ ** \\
\hline \multicolumn{5}{|l|}{ Father education } \\
\hline No formal Education & $502(43.4)$ & $656(56.6)$ & 1.48: $(1.17,1.89)^{\star \star}$ & 1.22: $(0.77,1.99)$ \\
\hline Have formal Education & $130(33.9)$ & $253(66.1)$ & 1 & 1 \\
\hline Family size & & & & \\
\hline
\end{tabular}




\begin{tabular}{|c|c|c|c|c|}
\hline \multirow[t]{2}{*}{ Variables $(n=1555)$} & \multicolumn{2}{|l|}{ Stunting } & \multirow[t]{2}{*}{ COR $(95 \% \mathrm{Cl})$} & \multirow[t]{2}{*}{ AOR $(95 \% \mathrm{Cl})$} \\
\hline & Yes (\#, \%) & No (\#, \%) & & \\
\hline$\geq 5$ family members & $455(44.3)$ & $573(55.7)$ & 1.57: $(1.26,1.95)^{\star \star}$ & 1.02: $(0.66,1.60)$ \\
\hline$<5$ Family members & 177(33.6) & $350(66.4)$ & 1 & 1 \\
\hline \multicolumn{5}{|l|}{ Sex of the children } \\
\hline male & $323(42.6)$ & $436(57.4)$ & 1.17: $(0.95,1.43)$ & 1.73: $(1.18,2.53)^{\star \star}$ \\
\hline Female & $309(38.8)$ & $487(61.2)$ & 1 & \\
\hline \multicolumn{5}{|l|}{ Membership } \\
\hline PSNP & $373(47.7)$ & $409(52.3)$ & 1.81: $(1.48,2.23)^{\star \star}$ & 1.82: $(1.14,2.89)^{\star}$ \\
\hline NPSNP & $259(33.5)$ & $514(66.5)$ & 1 & 1 \\
\hline
\end{tabular}

\section{Discussion}

The nutritional status of children is affected by different interwoven factors which may vary from location to location, and interhouseholds. This study was aimed at assessing the prevalence of stunting and its predictors among children aged 6-59 months living in households enrolled in productive safety net program and those non-enrolled in the program in Meta District of east Harerge zone of eastern Ethiopia. Accordingly, the prevalence of stunting was 47.7\% among children aged 6-59 months from PSNP beneficiaries and $35.5 \%$ for children who belong to NPSNP beneficiaries' households respectively. Stunting was significantly associated with lack of maternal education, women's inability to make decision, non-attendance of fourth antenatal care visit, practicing of hand washing during the critical periods, child's illness, lack of excusive breastfeeding, eating less diversified foods, and child 's age (being 24-59 months). However, being a beneficiary of PSNP did not show an association with stunting which needs to be more investigated using large scale study.

In this study, the prevalence of stunting among children aged 6-59 months in PSNP beneficiary and NPSNP beneficiary households was $47.7 \%$ and $33.5 \%$ respectively. This finding indicates a significant difference among the comparison groups. Similar finding was reported from Saesie Tsaeda Emba district, Tigray region, northern Ethiopia which implies that stunting is more common among food insecure households in Ethiopia. The prevalence of stunting observed in Saesie Tsaeda Emba district of productive safety net program beneficiary and non-productive safety net program households were $52.1 \%$ and $46.1 \%$ respectively [19].

Another national based study reported that the prevalence of stunting was higher among PSNP users (47\%) compared with NPSNP users (41.8\%) respectively [3]. This difference might be attributed to low food accessibility during months of food gaps among children from PSNP and NPSNP households. Food insecurity may be the result of low rainfall, highly sloppy and degraded farm land, and low productivity of the farm land to support the population's food yield [20].It is important that the existing PSNP needs to be upgraded to the level which satisfies the balanced food needs the of poor segment of the area's population.

The risk of stunting increases as the child's age increases. In this study, childen aged 24-59 months were 6. 9 times more likely to be stunted compared to children aged 6-23 months. This result was in line with the national figure [3] and study done in Belesa District [4], where children aged 24-35 months were more likely to be stunted when compared to earlier age group. This might be due to lack of continued child feeding practice with diversified diet and may be related to poor breast-feeding practice before the age of 23 months.

Stunting was also significantly associated with uneducated mothers/ care takers. The odds of stunting were nearly 4 times higher among chidren born to mothers who have no formal education compared to their counter parts. Similar finding was reported from South Wollo community, northern part of Ethiopia [21], Fadis District community, Hararghe Zone eastern Ethiopia [20] and study 
from Saesie Tsaeda-Emba District community, Tigray of north Ethiopia [19], and from Tanzania [22]. This might be attributed to the fact that child caring is mainly responsibility of the mother / care giver in Ethiopian context which is added to lack of knowledge of implementing appropriate to age child feeing practices and understanding of the adverse effects of undernutrition on children in the later life.

The odds of stunting were reduced by $62 \%$, among children from households who practice hand washing during the critical periods. This finding was consistent with study finding from northern part of the country [19]. This might be due to the efficiency of hand washing practice which can reduce pathogens that cause disease and thereby reduce stunting. It also implies in addition to other factors related chronic malnutrition an attempt needs to be made in scaling-up such cost effective intervention in reducing the magnitude of chronic malnutrition.

Children who had recovered from illness in the last 2 weeks of data collection periods were nearly 9 times more likely to be stunted than children who did not illness. This finding was comparable with community-based study done in, northwest Ethiopia [4]) and Latin America Amazon, Western Brazilian [23]. This might be due to increase in body's calorie requirement during illness and destruction of tissue as the result of the microorganisms among stunted children

Stunting was nearly 6 times more common among chidren of mothers who have not exclusively breastfed their children in the previous six months compared with their counter parts. This finding is agreement with community based study from Somali region of eastern Ethiopia [24], Saesie Tsaeda Emba district of north Ethiopia [19] and in rural Colombia [25]. This might be explained in such a way that breast milk has substantial amount of anti-infective substances that can safeguard children from the occurrence of infection thereby break malnutrition - infection viscious cycle

In this study, there was also a significant association between minimal dietary diversity and undernutrition. The odds of stunting was nearly 7 times higher among children who used to eat less diversified foods compared with their counter parts This result was comparable with findings of studies done in Saesie Tsaeda Emba district of northern Ethiopia [19], Somali region of eastern Ethiopia [24] and Colombia [25]. This result implies that diversified foods are very important for child growth and development during the age of 6-59 months in availing all micronutrients and macro nutrients for the body requirements

Children who born to mothers who were not able to make decision on the household issues were nearly 5 times more likely to have an increased odd of stunting compared with children born to empowered women to decide on households matters This finding was consistent with Maharashtra's study of Indians [6]. This might imply that when women are empowered to decide on household's matters the likelihood of caring for their children increases since they have access to household resources enhancing food accessibility for the household members.

Lack of proper antenatal care follow-up was also found to be associated the development of stunting. The odds of stunting were 7 times higher among children being delivered from mothers who did not attend their fourth ANC four follow-up when compared with their counterparts. Similar finding was reported from Yemen [7]. This might be due to the issues related to child nutrition often addressed during pregnancy upon consecutive ANC visit to alert pregnant women as how to feed their children after delivery in an attempt to prevent the onset of child undernutrition.

This study could have the following limitations. Firstly, some of the mother s /caregivers might have under or over reported their children's age, $t$ which could resulted in inappropriate estimation of the respective nutritional indices. However, age was estimated carefully based on mother's /caregiver/s unforgettable events such as public and religious holidays of the year using local calendar for those who did not have scientific background. Secondly, recall bias could be introduced upon collecting data on some past background variables such as 24 hours recall questions in which case an interactive 24 recall method was used to minimize such a bias. Thirdly, an anthropometric measurement error could potentially affect the results of this study due to both random and systematic error. Nevertheless, all important efforts such as calibration of measuring equipment, standardization procedure before deploying data enumerators to the field, and refreshment training for data enumerators were made to minimize the errors.

\section{Conclusions}

Page 12/16 
The prevalence of stunting is high among children from beneficiaries of safety net program compared with non-beneficiaries in the study area. Stunting was statistically significantly associated with lack of maternal education, maternal decision-making power, exclusive breastfeeding practice, fourth antenatal care, and adequate dietary diversity, presence of hand washing practices during critical periods and child's illness, and child's sex and age. Thus, intensifying women's decision making on household's matters including health services and improving infant and young child's feeding practices should be given attention to reduce the impacts of child's stunting by all relevant actors working in the area of child health program.

\section{Abbreviations}

EDHS: Ethiopia Demographic Health Survey, HAB: Household Asset Building Program, HH's: Households, HP: Health Post, UNICEF: United Nation Child Fund, WHO: World Health Organization, NPSNP: Non- Productive Safety Net Program, PSNP: Productive Safety Net Program, WHZ: Weight-for-height Z-score, WAZ: Weight-for-age Z-score, HAZ: Height-for-age Z-score, BCC: Behavioral Change Communication. AOR: adjusted odds ratio; COR: crude odds ratio.

\section{Declarations}

\section{Ethics approval and consent to participate}

The ethical clearance for this study was secured from the Institutional Health Research Ethics Review Committee (IHRERC) of the College of Health and Medical Sciences, Haramaya University. Participation in the study was voluntary and based on ability to give informed written consent. Participants were guaranteed confidentiality for the information collected. Non-participation was not having negative effect on their children's care services. All undernourished children identified during data collection period were linked to appropriate community based therapeutic feeding program.

\section{Consent for publication}

Not applicable

\section{Availability of data and materials}

The datasets used and/or analyzed in this study will be made available by the corresponding author upon reasonable request

\section{Competing interests}

The authors declare that they have not any competing interests.

\section{Funding}

None

\section{Authors' contributions}

TA was conceived the idea of this study, prepared data collection questionnaires, conducted data collection, data entry, analyses, and interpretation and critically reviewed the manuscript. EG assisted with conceptualizing the design of the study as well as analysis, data interpretation and critical review of the manuscript. All authors read and approved the final manuscript.

\section{Acknowledgements}

We would like to thank Haramaya University and Meta district health office for facilitating the survey work by providing us with all rounded support in providing the necessary information. Our most gratitude goes to data collectors, supervisors and study participants also deserve our appreciation

\section{References}


1. UNICEF. Improving Child Nutrition. The achievable imperative for global progress, 2013. Available at: https://www.unicef.org/publications/index_68661.html.Date accessed: 20/October/2020.

2. World Health Organization (WHO). Global Nutrition report, 2018. Shining a light to spur action on nutrition. Availble at: https://globalnutritionreport.org/reports/global-nutrition-report-2018/.Date accessed: 20/ October 2020.

3. Central Statistical Agency (CSA) . Ethiopia Demographic and Health Survey(EDHS). Key Indicators Report. .Available at: https://dhsprogram.com/pubs/pdf/FR328/FR328.pdf .Date Accessed: 20/October/2020.

4. Fentahun W, Wubshet M, Tariku A. Undernutrition and Associated Factors among Children Aged 6-59 Months in East Belesa District, Northwest Ethiopia: A Community Based Cross-Sectional Study. BMC Public Health, 2016; 16: 506.

5. Motbainor A, Worku A, Kumie A. Level and Determinants of Food Insecurity in East and West Gojjam Zones of Amhara Region, Ethiopia: A Community Based Comparative Cross-Sectional Study. BMC Public Health,2016; 16: 503.

6. AguayoVM, NairR, BadgaiyanN, Krishna, V. Determinants of stunting and poor linear growth in children under 2 years of age in India: an in-depth analysis of Maharashtra's comprehensive nutrition survey. Matern Child Nutr, 2016; 12 Suppl.(1): 121-40.

7. Sobaihi S, Nakamura K, Kizuki M. Undernutrition among Children under 5 Years of Age in Yemen: Role of Adequate Childcare Provided by Adults under Conditions of Food Insecurity. J Rural Med. 2016; 11(2): 47-57.

8. Berhanu , G, Mekonnen, S, Sisay M. Prevalence of stunting and associated factors among preschool children: A community based comparative cross sectional study in Ethiopia. BMC Nutrition 2018, 4:28.

9. Global facility for disaster reduction \& recovery( GFDRR). Ethiopia's Productive Safety Net Program (PSNP) Integrating Disaster And Climate Risk Management CASE, 2013. Available at: http://documents1.worldbank.org/curated/en/893931468321850632/pdf/806220WPOP12680Box0379812B00PUBLIC0.pdf.

10. Tafere Y, Woldehanna T. 2012. Beyond Food Security: Transforming the Productive Safety Net Programme in Ethiopia for the Well-Being of Children. Available at: https://younglives-ethiopia.org/sites/www.younglives-ethiopia.org/files/YLWP83_Tafere_revised_Jan2013_0.pdf.Date accessed: 20/October /2020.

11. Ministry of Agriculture (MOA). Productive Safety Net Program Phase 4 (PSNP 4). Enhanced Social Assessment And Consultation Final Report , 2014.

12. Food and Agriculture Organization (FAO): African Food Security Prospects Brighter Than Ever. Regional Overview of Food Insecurity Africa , 2015. Available at: http://www.fao.org/3/a-i4635e.pdf.Date accessed: 28/October/2020.

13. Food and Agriculture Organization (FAO): Federal Democratic Republic of Ethiopia. National Nutrition Program II 2016-2020, 2016, Addis Ababa, Ethiopia. Available at: http://extwprlegs1.fao.org/docs/pdf/eth190946.pdf. Date accessed:

28/October/2020.

14. Federal Democratic Republic of Ethiopia Population Census Commission, 2008. Summary and statistical report of the 2007 population and housing census : Population by age and sex .Available at: https://www.ethiopianreview.com/pdf/001/Cen2007_firstdraft(1).pdf.Date accessed : 28/October/2020.

15. Meta District disaster prevention and preparedness office (DPPO) report of 2017(Unpublished).

16. Cogill B. Anthropometric Indicators Measurement Guide, Food And Nutrition Technical Assistance, 2003. Available at: https://www.fantaproject.org/tools/anthropometry-guide.Date accessed: 28/October/2020.

17. World Health Organization (WHO). Nutrition Landscape Information System (NLIS) Country Profile Indicators. Interpretation guide 2010. Available at: https://www.who.int/nutrition/nlis_interpretation_guide.pdf.Date accessed: 28/October/2020.

18. Perini TA, de Oliveira1 GL, dos Santos Ornellas J, de Oliveira FP. Technical error of measurement in anthropometry. Rev Bras Med Esporte 2005; 11(1): 86-90.

19. Amaha Kahsay A, Mulugeta A, Seid O. Nutritional Status of Children (6-59 Months) from Food Secure and Food InsecureHouseholds in Rural Communities of Saesie Tsaeda-Emba District, Tigray, North Ethiopia: Comparative Study. Clinical Medicine Research 2015; 4(1): 51-65. doi: 10.11648/j.ijnfs.20150401.18.

20. Kassa WA .Impact of productive safety net program in rural community of Ethiopia: A review study. Journal of Agricultural Extension and Rural Development 2018; 10(5): 84-88.

21. Andersson C., Mekonnen A. and Stage J. Impacts of the Productive Safety Net Program in Ethiopia on livestock and tree holdings of rural households. Journal of Development Economics, 2011; 94 (Issue 1) ; 119-126.

Page 14/16 
22. Semali IA, Tengia-Kessy A, Mmbaga EJ, Leyna G.Prevalence and determinants of stunting in under-five children in central Tanzania: remaining threats to achieving Millennium Development Goal 4.BMC Public Health 2015; 15:1153.

23. Mantovani SAS, Ramalho AA, Pereira TM, Castelo Branco FLC, Oliart-Guzmán H, Delfino BM et al,. Stunting in children under five years old is still a health problem in the Western Brazilian Amazon: a population-based study in Assis Brasil, Acre, Brazil. . Cien Saude Colet, 2016; 21(7) : 2257-66.

24. Fekadu Y, Mesfin A, Haile D, J. Stoecker B. Factors associated with nutritional status of infants and young children in Somali Region, Ethiopia: a cross- sectional study. BMC Public Health , 2015 ; 15:846 DOI 10.1186/s12889-015-2190-7.

25. Reinbott A, Schelling A, Kuchenbecker J , Jeremias T, Russell I, Kevanna OU , B. Krawinkel M, Jordan I. Nutrition Education Linked to Agricultural Interventions Improved Child Dietary Diversity in Rural Cambodia. British Journal of Nutrition, $2016 ; 116$ : 1457-1468 Br J Nutr, 116: 1457-1468. doi:10.1017/S0007114516003433.

\section{Figures}

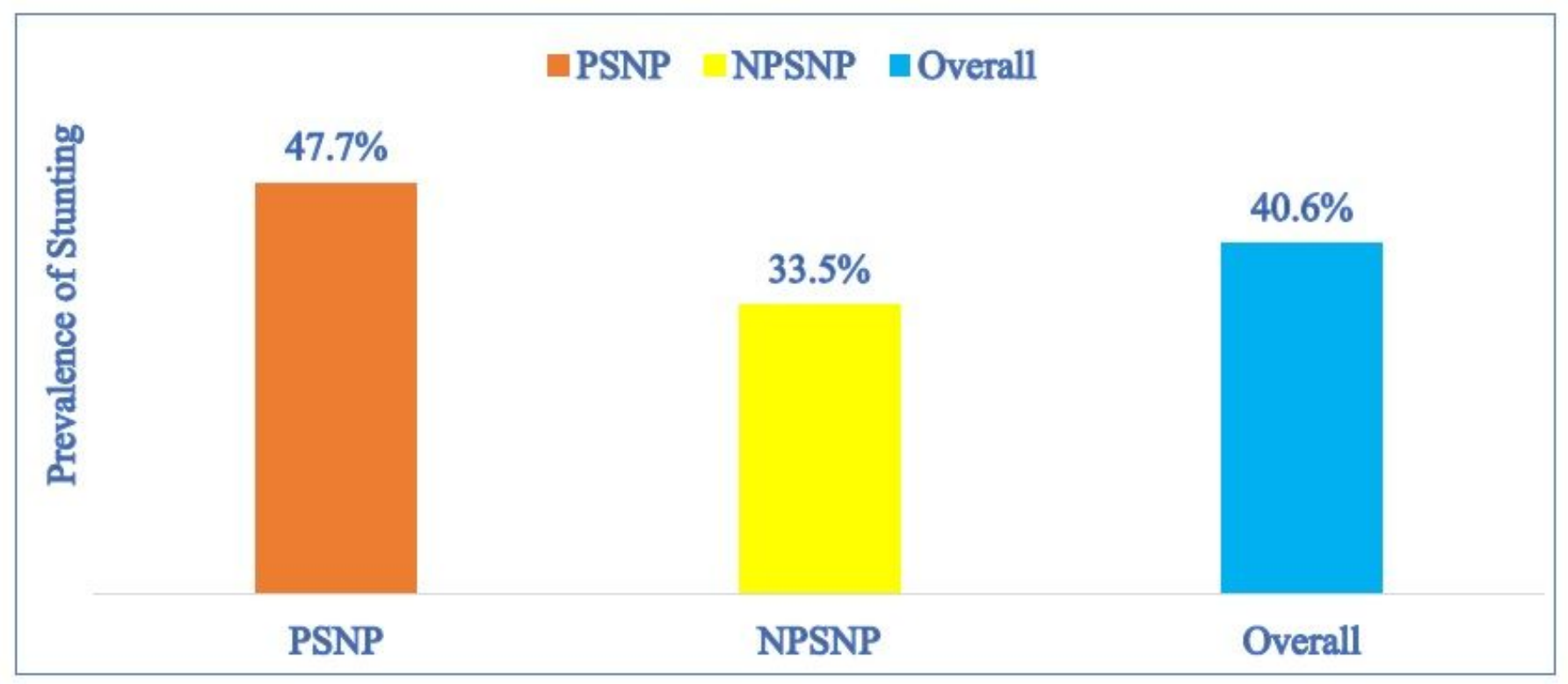

\section{Figure 1}

Prevalence of Stunting among children aged 6-59 months in PSNP and NPSNP household Meta District, March 2017.

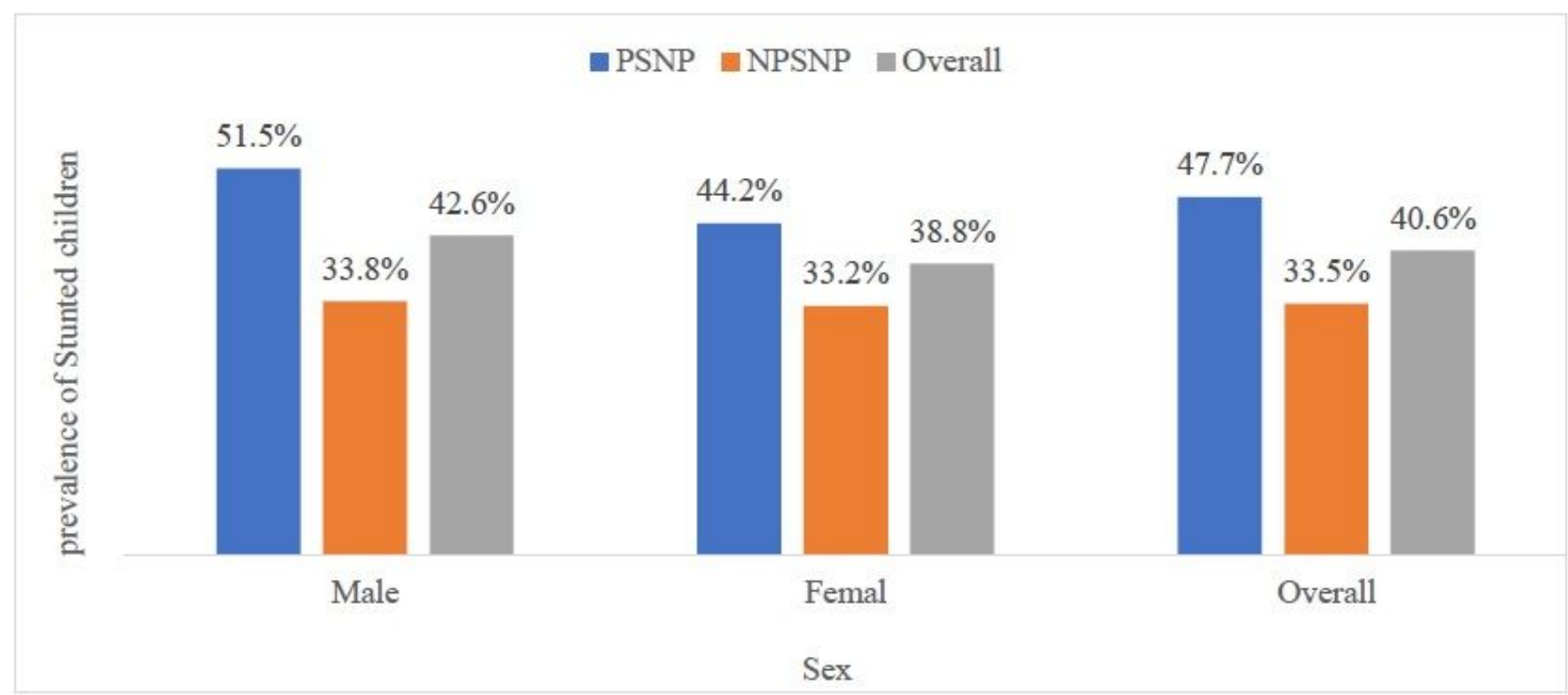


Figure 2

Prevalence of stunting among children disaggregated by sex across PSNP and NPSNP beneficiary households, Meta District, March 2017.

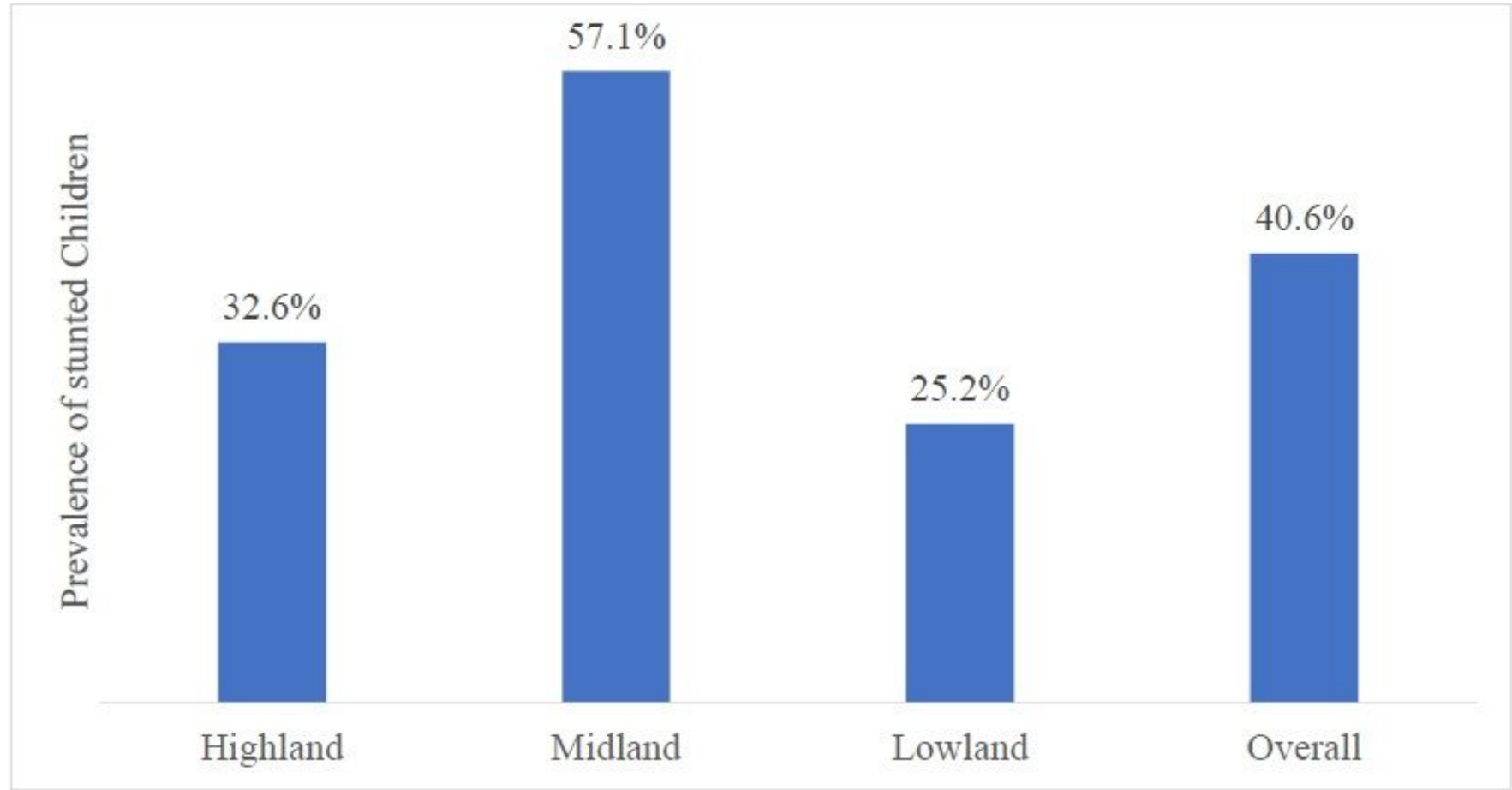

\section{Figure 3}

Prevalence of stunting among children across the three agroecological zones, Meta District, March 2017. 